\title{
Investigating Tactile Stimulation in Symbiotic Systems
}

\author{
Valeria Orso ${ }^{1(\bowtie)}$, Renato Mazza ${ }^{1}$, Luciano Gamberini ${ }^{1}$, \\ Ann Morrison ${ }^{2}$, and Walther Jensen ${ }^{2}$ \\ ${ }^{1}$ Human Inspired Technologies Research Centre, Padua University, Padua, Italy \\ \{valeria. orso, luciano.gamberini\}@unipd.it, \\ renatomazza.89@gmail.com \\ 2 Department of Architecture Design and Media Technology, \\ Aalborg University, Aalborg, Denmark \\ \{morrison,bwsj\}@create.aau.dk
}

\begin{abstract}
The core characteristics of tactile stimuli, i.e., recognition reliability and tolerance to ambient interference, make them an ideal candidate to be integrated into a symbiotic system. The selection of the appropriate stimulation is indeed important in order not to hinder the interaction from the user's perspective. Here we present the process of selecting the most adequate tactile stimulation delivered by a tactile vest while users were engaged in an absorbing activity, namely playing a video-game. A total of 20 participants (mean age 24.78; $S D=1.57$ ) were involved. Among the eight tactile stimuli selected, we found that the most frequently chosen stimulus was the one stimulating the back of the participant from the upper to the lower area.
\end{abstract}

Keywords: Wearable device $\cdot$ Tactile stimulation $\cdot$ Symbiotic system

\section{Introduction}

Tactile interfaces take advantage of the sense of touch, particularly stimulating mechanoreceptors in the skin, to deliver feedbacks to the user [1, 2]. Tactile displays have proved to be an effective and powerful means for communicating information to users, even when they are already engaged in another activity (e.g., working) users can reliably comprehend messages enclosed in the tactile mode [3, 4]. Given the size of the actuators, tactile displays are usually implemented as wearable computers [5], i.e., fully functional and self-contained electronic devices to be worn and allowing the user to have constant access to information [6]. As already noted by [6], wearable computers are an ideal component of symbiotic systems (i.e., systems that record and interpret a user's cognitive and affective states and respond accordingly), given their ubiquitous and portable nature.

The integration of tactile displays in symbiotic systems could enhance the interaction between the user and the system. Differently from visual or acoustic feedback, tactile stimulations are reliable, because they are tolerant to ambient interference [7]. Furthermore, tactile stimuli require less attentional resources to be processed and lead to natural and fast responses [7, 8]. In sum, a symbiotic system including tactile 
stimulations could deliver subtle and unobtrusive feedbacks to the user, thus allowing him/her to keep the interaction focus on the environment [2]. Nevertheless, a proper selection of the tactile stimuli is needed, since the delivery of annoying stimulation could instead disturb and distract the user.

The experiment presented here aimed at identifying the most suitable tactile stimuli delivered through a tactile vest while the user was engaged in an involving activity, namely playing a video-game. In addition, we tested if the preferences emerged were consistent during the entire experimental session. The method employed was devised and comprised both objective data from users' interaction and subjective data from interviews.

\section{Equipment}

The tactile vest was designed to produce vibrotactile sensations resembling the touch patterns made by kinesiologist-neurophysiologists to activate or calm down a person [9]. The vest is composed of two layers: the inner layer holds 44 actuators and the outer layer keeps the actuators tight to the wearer's skin [9]. All actuators are attached through moveable Velcro patches to adjust their position according to different body sizes (Fig. 1). The vest is connected over Bluetooth with an Android tablet (Nvidia Shield Tablet K1) and a dedicated application was developed to activate the tactile stimuli.

We selected eight of the patterns that prior results [9] had shown either activated or calmed vest wearers. The stimuli were designed with overlapping transitions to create a smooth flowing sensation [9]. Details for each stimulus can be found in Table 1.
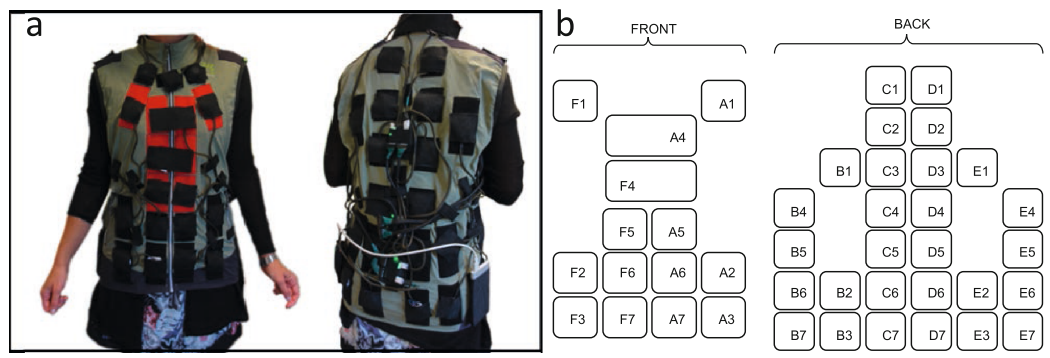

Fig. 1. The tactile vest. (a) A frontal (left) and rear (right) view of the inner layer of the tactile vest. The black male patches hold the actuators tight against the female patches on the vest. (b) A schematic representation of the actuators placement.

\section{Experimental Procedure and Metrics}

The user was first debriefed on the overall procedure and the goals of the activity. Then s/he signed an informed consent form. The participant wore the tactile vest, sat at the desk and then the training phase started. The experimenter activated all the different tactile 
Table 1. A description of the stimuli selected. The pattern sequence of the actuators activated, the duration of activation of each pattern, the duration of the overlapping transition and the amplitude of the vibration.

\begin{tabular}{|c|c|c|c|c|}
\hline Stimulus & Pattern sequence & Duration & Overlap & Amplitude \\
\hline$\# 1$ & $\begin{array}{l}{[\mathrm{C} 7, \mathrm{D} 7][\mathrm{C} 6, \mathrm{D} 6][\mathrm{C} 5, \mathrm{D} 5][\mathrm{C} 4, \mathrm{D} 4]} \\
{[\mathrm{C} 2, \mathrm{D} 2][\mathrm{C} 1, \mathrm{D} 1]}\end{array}$ & 350 & 175 & $100 \%$ \\
\hline$\# 2$ & {$[\mathrm{~B} 2, \mathrm{E} 2][\mathrm{B} 2, \mathrm{~B} 3, \mathrm{E} 2, \mathrm{E} 3][\mathrm{B} 3, \mathrm{E} 3]$} & 450 & 175 & $100 \%$ \\
\hline$\# 3$ & $\begin{array}{l}\text { A3 [F1, A1] [C1, D1, B1, E1] [C2, D2] } \\
{[\mathrm{C} 3, \mathrm{D} 3][\mathrm{C} 4, \mathrm{D} 4][\mathrm{C} 5, \mathrm{E} 5][\mathrm{C} 6, \mathrm{D} 6][\mathrm{C} 7,} \\
\mathrm{D} 7][\mathrm{C} 6, \mathrm{D} 6][\mathrm{C} 5, \mathrm{D} 5][\mathrm{C} 4, \mathrm{D} 4][\mathrm{C} 3, \mathrm{D} 3] \\
{[\mathrm{C} 2, \mathrm{D} 2][\mathrm{C} 1, \mathrm{D} 1]}\end{array}$ & 350 & 175 & $85 \%$ \\
\hline$\# 4$ & $\begin{array}{l}{[\mathrm{C} 6, \mathrm{C} 7, \mathrm{D} 6, \mathrm{C} 7][\mathrm{B} 6, \mathrm{~B} 7, \mathrm{E} 6, \mathrm{E} 7][\mathrm{F} 2,} \\
\mathrm{F} 3, \mathrm{~A} 2, \mathrm{~A} 3][\mathrm{F} 6, \mathrm{~F} 7, \mathrm{~A} 6, \mathrm{~A} 7][\mathrm{F} 6, \mathrm{~A} 6] \\
{[\mathrm{F} 6, \mathrm{~F} 7, \mathrm{~A} 6, \mathrm{~A} 7][\mathrm{F} 2, \mathrm{~F} 3, \mathrm{~A} 2, \mathrm{~A} 3][\mathrm{B} 6,} \\
\mathrm{B} 7, \mathrm{E} 6, \mathrm{E} 7][\mathrm{B} 2, \mathrm{~B} 3, \mathrm{E} 2, \mathrm{E} 3][\mathrm{C} 6, \mathrm{C} 7, \\
\text { D6, D7] }\end{array}$ & 400 & 100 & $100 \%$ \\
\hline$\# 5$ & $\begin{array}{l}\text { A4 [F1, A1] [C1, D1, B1, E1] [C2, D2] } \\
{[\mathrm{C} 3, \mathrm{D} 3][\mathrm{C} 4, \mathrm{D} 4][\mathrm{C} 5, \mathrm{D} 5][\mathrm{C} 6, \mathrm{D} 6]} \\
{[\mathrm{C} 7, \mathrm{D} 7]}\end{array}$ & 500 & 400 & $85 \%$ \\
\hline \#6 & $\begin{array}{l}\text { A4 [F1, A1] [C1, D1, B1, E1] [C2, D2] } \\
{[\mathrm{C} 3, \mathrm{D} 3][\mathrm{C} 4, \mathrm{D} 4][\mathrm{C} 5, \mathrm{D} 5][\mathrm{C} 4, \mathrm{D} 4]} \\
{[\mathrm{C} 3, \mathrm{D} 3][\mathrm{C} 2, \mathrm{D} 2][\mathrm{C} 1, \mathrm{D} 1]}\end{array}$ & 500 & 400 & $85 \%$ \\
\hline$\# 7$ & $\begin{array}{l}{[\mathrm{F} 1, \mathrm{~A} 1][\mathrm{F} 1, \mathrm{~A} 1][\mathrm{A} 4][\mathrm{A} 4][][\mathrm{F} 1, \mathrm{~A} 1]} \\
{[\mathrm{A} 4][\mathrm{A} 4]}\end{array}$ & 500 & 200 & $85 \%$ \\
\hline$\# 8$ & $\begin{array}{l}{[\mathrm{F} 1, \mathrm{~A} 1][\mathrm{F} 1, \mathrm{~A} 1][\mathrm{A} 4][\mathrm{A} 4][\mathrm{F} 1, \mathrm{~A} 1]} \\
{[\mathrm{F} 1, \mathrm{~A} 1][\mathrm{A} 4][\mathrm{A} 4][\mathrm{F} 1, \mathrm{~A} 1][\mathrm{F} 1, \mathrm{~A} 1]}\end{array}$ & 500 & 200 & $85 \%$ \\
\hline
\end{tabular}

stimuli while the user started to play the video game using a desktop PC (21" monitor) and the computer mouse, in order to make him/her familiar with the task, for an approximate duration of $4 \mathrm{~min}$. After that, the actual experimental session started and lasted about $8 \mathrm{~min}$. During the experimental trail the user was asked to play a popular video-game called Puzzle-Bubble ${ }^{1}$ and to activate the tactile stimuli s/he preferred at his/her will by tapping on the tablet paired with the tactile vest. After the experimental session ended, participants answered a brief interview.

A total of 20 people volunteered for the study, 6 of them were male. The mean age of the sample was 24.78 years old $(\mathrm{SD}=1.57)$. Participants were recruited by word of mouth and only one of them had never played Puzzle Bubble before. None of them reported to be a regular video-game player. Participants received no compensation for taking part in the study.

\footnotetext{
${ }^{1}$ The video-game was selected in a preliminary test. The goal of the game is to clear all the bubbles from the board by shooting one colored bubble at a time. Every time the bubble shot hits a group of three or more bubbles of the same color, the group of bubbles hit disappear.
} 


\section{Results}

Users' preferences for the different tactile stimuli can be divided in three temporal intervals, each lasting about $4 \mathrm{~min}$. The first interval corresponded with the training phase; the second interval corresponded to the first half of the experimental session and the third one coincided with the second half of the experimental trail. The data logged during the training were excluded from the analysis. For the first and second temporal intervals of the experimental session, we computed the percentage of times each tactile stimulus was chosen and then compared it against the expected frequency if users chose that stimulus randomly, i.e., $12.5 \%$, through a one-sample t-test.

Considering the first temporal interval, we found that the stimulus participants chose the most was \#3, t19 = 2.6 p = .017 $(\mathrm{M}=19.81 ; \mathrm{SD}=12.54)$. The analysis also showed that there were two stimuli that participants chose significantly less often than the expected frequency. One was \#1, t19 = 3.43 p =.003 (M=6.9; SD = 7.29); while the other one was \#5, t19 = $2.9 \mathrm{p}=.007(\mathrm{M}=7.17$; SD = 7.94). The rate with which the other stimuli were chosen did not significantly differ form the expected choice rate, detailed values are reported in Table 2.

Regarding the second temporal interval considered, we found that Stimuli \#1 and \#5 were again chosen to a significantly lower rate than expected, respectively $\mathrm{t} 19=3.31 \mathrm{p}=.004(\mathrm{M}=6.51 ; \mathrm{SD}=8.08)$ and $\mathrm{t} 19=2.30 \mathrm{p}=.033 \quad(\mathrm{M}=7.04 ;$ $\mathrm{SD}=10.58)$. All the other stimuli were chosen with a selection rate that did not significantly differ from the expected choice rate, see Table 2 for detailed values.

Considering the entire experimental session, Stimuli \#1 and \#5 confirmed to be the least preferred ones, $\mathrm{t} 19=4.58 \mathrm{p}<.001(\mathrm{M}=6.55 ; \mathrm{SD}=5.47)$ and $\mathrm{t} 19=2.29$ $\mathrm{p}=.009(\mathrm{M}=7.09 ; \mathrm{SD}=8.25)$, respectively. Stimuli \#3 confirmed to be the most chosen one, $\mathrm{t} 19=3.15 \mathrm{p}=.005(\mathrm{M}=20.15 ; \mathrm{SD}=10.84)$. An overview of the results is depicted in Fig. 2.

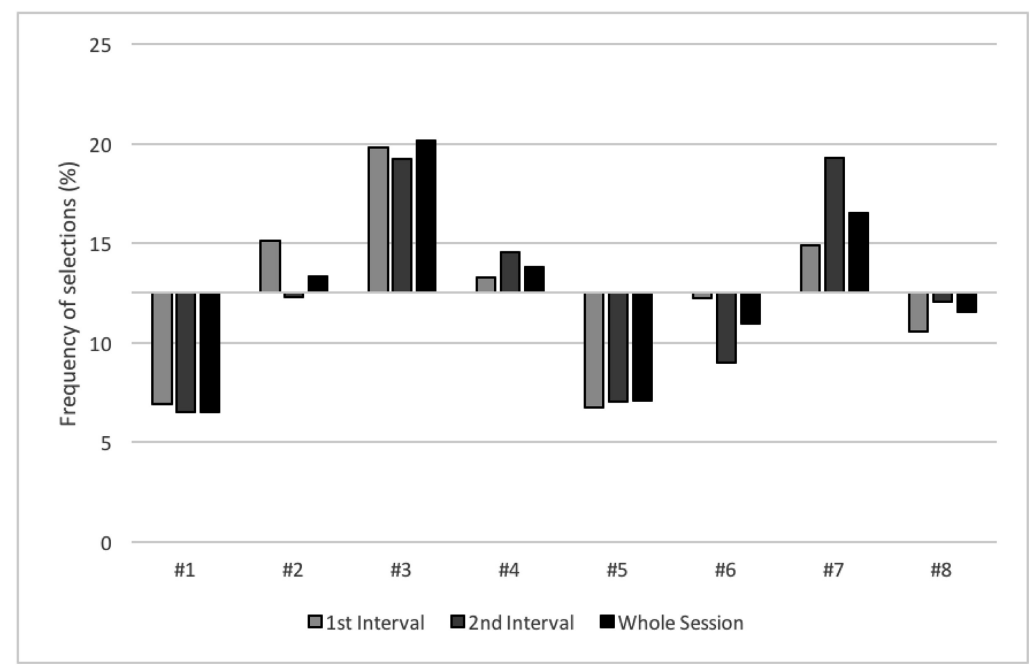

Fig. 2. The choice rate per stimuli throughout the experimental session. The origin of the graph is set at $12.5 \%$, which is the expected casual choice rate. $* p<.05$ 
Table 2. The values of the one sample t-test, average selection rate and standard deviations for each of the stimuli participants are reported. $* p<.05$

\begin{tabular}{l|c|c|l|l|r|r}
\hline \multirow{2}{*}{ Stimulus } & \multicolumn{2}{|l|}{ First interval } & \multicolumn{2}{l|}{ Second interval } & \multicolumn{2}{l}{ Whole session } \\
\cline { 2 - 7 } & \multicolumn{1}{l|}{$\mathrm{t}$} & $\mathrm{M}(\mathrm{SD})$ & $\mathrm{t}$ & $\mathrm{M}(\mathrm{SD})$ & $\mathrm{t}$ & $\mathrm{M}(\mathrm{SD})$ \\
\hline$\# 1$ & $3.43 *$ & $6.9(7.29)$ & $3.31 *$ & $6.51(8.08)$ & $4.85^{*}$ & $6.55(5.47)$ \\
\hline$\# 2$ & .085 & $15.12(13.71)$ & 0.039 & $12.3(22.38)$ & .255 & $13.31(14.23)$ \\
\hline$\# 3$ & $2.60 *$ & $19.81(12.54)$ & 1.917 & $19.21(15.66)$ & $3.15^{*}$ & $20.15(10.84)$ \\
\hline$\# 4$ & .28 & $13.25(11.62)$ & 0.77 & $14.56(11.91)$ & .615 & $13.8(9.49)$ \\
\hline$\# 5$ & $2.99 *$ & $7.17(7.94)$ & $2.30 *$ & $7.04(10.58)$ & $2.29 *$ & $7.09(8.25)$ \\
\hline$\# 6$ & .116 & $12.21(11.37)$ & 1.78 & $8.99(8.79)$ & .847 & $10.97(8.02)$ \\
\hline$\# 7$ & .952 & $14.92(11.37)$ & 1.98 & $19.28(15.26)$ & 1.54 & $16.53(11.70)$ \\
\hline$\# 8$ & .904 & $10.59(9.42)$ & .152 & $12.09(12.03)$ & .46 & $11.56(8.87)$ \\
\hline
\end{tabular}

Interview data indicate that half of the sample $(\mathrm{n}=10)$ affirmed that they tended to choose a single stimulus, whilst three of them said they tried different stimuli. Two participants said they activated different stimuli at random and three reported that they first tried different stimuli and then selected their favorite one. When asked to motivate their choice, twelve participants said they selected a particular vibrational pattern because they found it pleasant. One affirmed that the vibration helped him/her to concentrate in the game and one that they were relaxing. Three participants reported the tactile stimuli to be activating. Finally, only one user affirmed that the vibrations were distracting.

\section{Conclusions}

The experiment presented here aimed at identifying vibrational stimuli that could be integrated into a symbiotic system. By asking participants to freely choose the stimulation they preferred, we found that the stimulus users favored was characterized by a vibrational pattern activated from the upper toward the lower area of the back. Interestingly, the vibration of the same set of actuators, yet activated in the reverse order, which characterized Stimulus \#1, was the least chosen stimulus. This finding suggests that besides the basic parameters characterizing a tactile stimulus, i.e., the intensity, the rhythm and the area on the body on which the tactile stimuli are applied [4], developers should also take into account the feeling that a given stimulation produces on the user. As emerged from the interviews, participants' choices were mainly motivated by the pleasantness of the stimuli.

In addition, we found that participants' preferences were overall stable throughout the entire experimental session, suggesting that when a tactile stimulation is perceived as (un)pleasant the feeling persists over time.

The investigation of tactile stimulation embedded into a symbiotic system needs to be extended to other wearable devices integrating a tactile interface, e.g., tactile glove, tactile wrist-band. Finally, in order to build a clear understanding of how tactile stimulations can be successfully employed in a symbiotic system, further experiments are required to understand the impact of tactile stimuli over longer interactions. 
Acknowledgments. The present study was partially funded by the EU project CultAR (grant agreement n. 601139).

\section{References}

1. O’Malley, M.K., Gupta, A.: Haptic interfaces. In: Kortum, P. (ed.) HCI Beyond the GUI: Design for Haptic, Speech, Olfactory, and Other Nontraditional Interfaces, pp. 25-64. Elsevier Inc., Amsterdam (2008)

2. Jacob, R., Mooney, P., Winstanley, A.C.: Guided by touch: tactile pedestrian navigation. In: Proceedings of the 1st International Workshop on Mobile Location-Based Service, pp. 11-20. ACM (2011)

3. Tsukada, K., Yasumura, M.: ActiveBelt: belt-type wearable tactile display for directional navigation. In: Davies, N., Mynatt, E.D., Siio, I. (eds.) UbiComp 2004. LNCS, vol. 3205, pp. 384-399. Springer, Heidelberg (2004). doi:10.1007/978-3-540-30119-6_23

4. Hoggan, E., Anwar, S., Brewster, S.A.: Mobile multi-actuator tactile displays. In: Oakley, I., Brewster, S. (eds.) HAID 2007. LNCS, vol. 4813, pp. 22-33. Springer, Heidelberg (2007). doi:10.1007/978-3-540-76702-2_4

5. Carton, A., Dunne, L.E.: Tactile distance feedback for firefighters: design and preliminary evaluation of a sensory augmentation glove. In: Proceedings of the 4th Augmented Human International Conference, pp. 58-64. ACM (2013)

6. Spagnolli, A., Guardigli, E., Orso, V., Varotto, A., Gamberini, L.: Measuring user acceptance of wearable symbiotic devices: validation study across application scenarios. In: Jacucci, G., Gamberini, L., Freeman, J., Spagnolli, A. (eds.) Symbiotic 2014. LNCS, vol. 8820, pp. 8798. Springer, Cham (2014). doi:10.1007/978-3-319-13500-7_7

7. Ahmaniemi, T.T., Lantz, V.T.: Augmented reality target finding based on tactile cues. In: Proceedings of the 2009 International Conference on Multimodal Interfaces, pp. 335-342. ACM (2009)

8. Hornecker, E., Swindells, S., Dunlop, M.: A mobile guide for serendipitous exploration of cities. In: Proceedings of MobileHCI, pp. 557-562. ACM (2011)

9. Morrison, A.J., Manresa-Yee, C., Knoche, H., Jensen, B.W.S., Leegaard, J.: Interactive furniture: bi-directional interaction with a vibrotactile wearable sensate vest in an urban space. In: Recent Advances in Technologies of Inclusive Well-Being (in press)

Open Access This chapter is licensed under the terms of the Creative Commons Attribution 4.0 International License (http://creativecommons.org/licenses/by/4.0/), which permits use, sharing, adaptation, distribution and reproduction in any medium or format, as long as you give appropriate credit to the original author(s) and the source, provide a link to the Creative Commons license and indicate if changes were made.

The images or other third party material in this chapter are included in the chapter's Creative Commons license, unless indicated otherwise in a credit line to the material. If material is not included in the chapter's Creative Commons license and your intended use is not permitted by statutory regulation or exceeds the permitted use, you will need to obtain permission directly from the copyright holder.

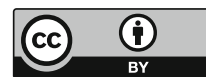

